\title{
Utility of molecular-assisted alpha taxonomy of the genus Cystophora (Fucales, Phaeophyceae) from New Zealand and Australia
}

\author{
Joe Buchanan and Giuseppe C. Zuccarello* \\ School of Biological Sciences, Victoria University of Wellington, P.O. Box 600, Wellington 6140, New Zealand
}

\begin{abstract}
AвSTRACT: Many brown macroalgal species are difficult to identify because of limited morphological differentiation and/ or high levels of plasticity. Molecular methods for distinguishing species coupled with morphological examination have been useful in clarifying species status in many groups. Cystophora is a species-rich, morphologically complex brown algal genus that has been carefully monographed, and it is ideal for testing the utility of molecular markers for genetic species delimitation. We evaluated the utility of the cytochrome oxidase subunit 1 (COI) DNA-barcode marker, alone and in combination with nuclear-encoded internal transcribed spacer (ITS) rDNA, in delimiting species. We also used several methods to delimit putative genetic species. Our results showed that for consistent species delimitation and species delimitation that approximates morphological species, both markers in combination are necessary. Most species in the genus are morphologically recognizable and genetically distinct but neither COI nor combined COI-ITS data separate Cystophora congesta from Cystophora retroflexa or Cystophora distenta from Cystophora scalaris. We showed that morphological characters used to separate these two species pairs are highly variable among samples, with many intermediates. Thus, we concluded that these are not independent species and synonymize these species. Our data showed that this genus, while widespread, mostly conforms to a morphospecies concept.
\end{abstract}

Key Words: COI, DNA barcoding, ITS, Morphology, Nomenclature, Sargassaceae, Species delimitation, Synonymization

\section{INTRODUCTION}

DNA barcoding uses base pair differences among short sequences, usually a section of mitochondria-encoded cytochrome oxidase subunit 1, for species identification (Hebert et al. 2003, 2004). While DNA barcoding relies on an existing taxonomy, short DNA sequences have also been used to reveal 'new species' in groups of organisms. This molecular-assisted alpha taxonomy method (Cianciola et al. 2010) has been very useful in revealing the diversity and the taxonomy of marine algae. DNA based methods that circumscribe clusters of genetically similar entities can help untangle morphological variation resulting from phenotypic plasticity from morphological characters that correlate with species-level genetic isolation. This is important in organisms that are known to vary greatly in their morphology in various environments and/or in organisms that have few morphological characters, like brown algae. Numerous genetic methods have been developed to delimit potential species. They rely on assumptions of differences between speciation events and population evolutionary processes (Lelieart et al. 2014).

DNA barcoding and molecular-assisted taxonomy in the Phaeophyceae have used a single marker (McDevit \& Saunders 2010; Peters et al. 2015) or multiple genes (Lane et al. 2007; McDevit \& Saunders 2010; González et al. 2012; Vieira et al. 2014; Kogame et al. 2015; Diaz-Martinez et al. 2016; Hoshino et al. 2018) with variable success. Two common DNA barcoding regions are the $5^{\prime}$ end of the cytochrome oxidase subunit 1 (COI) and the nuclear-

* Corresponding author (joe.zuccarello@vuw.ac.nz).

DOI: $10.2216 / 17-78.1$

(C) 2018 International Phycological Society encoded ribosomal internal transcribed spacer regions (ITS1-5.8S-ITS2 rDNA cistron, henceforth ITS).

COI barcoding of brown algae has had mixed success. Lane et al. (2007) investigated species delimitation using COI in north-east Pacific species of Alaria and found that clusters of COI haplotypes were not congruent with a priori morphological species assignments, nor with clades inferred from ITS sequences. Lane et al. (2007) suggested that widespread introgressive hybridisation precludes molecular delimitation of species of Alaria in the study region. McDevit \& Saunders (2010) extensively sampled Canadian Laminariaceae and were able to resolve most species, with intraspecific distances. However, Saccharina latissima had moderate within species divergence $(1.2 \%)$, forming geographically distinct clusters, and also low inter-specific distances (2.1\% between Saccharina bongardiana and Saccharina groenlandica). Mattio \& Payri (2010) compared COI and four other markers in Sargassum subgenus Sargassum. COI performed better than other markers but within species distances (c. 0-2\%) and between species distances (c. 0.5$7.3 \%$ ) overlapped. How these markers will perform in delimiting species and how these genetic delimitations correspond to morphological species is not known in many other brown algal genera.

In this study we compare the utility of COI clusters $(=$ genetic species) to a priori identified morphological species (= morphospecies) in the genus Cystophora J.Agardh (Sargassaceae, Fucales) and compare this species delimitation also using combined concatenated COI and ITS datasets. Cystophora is an ideal genus for testing this approach, since a thorough morphological taxonomy is available for comparison (Womersley 1964, 1987). The genus is relatively speciose (23 species listed in Womersley 1964) and includes species with clear morphological boundaries and others 


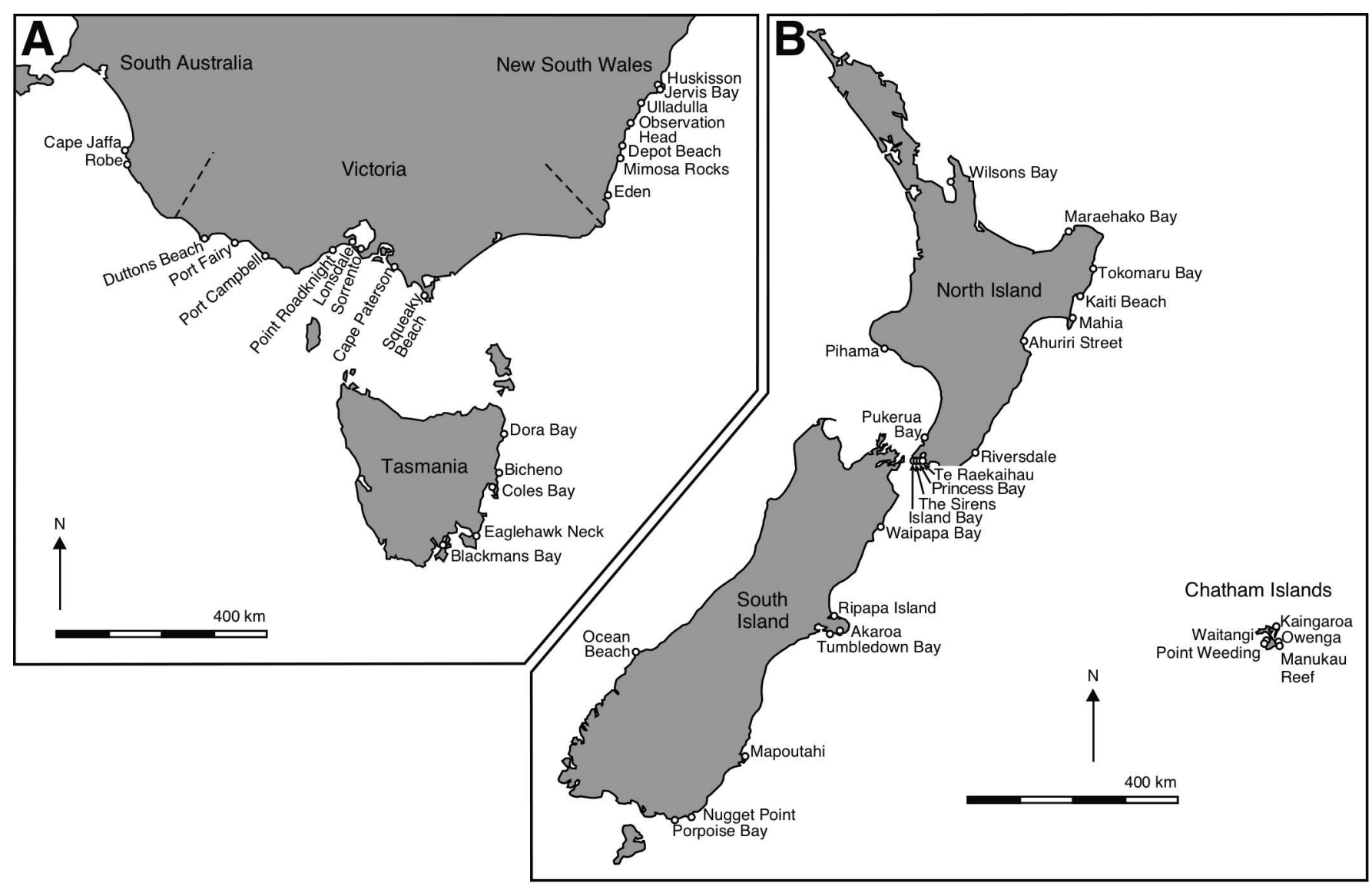

Fig. 1. Map indicating sampling locations for the study (see Table S1 for more details). (A) Southern Australia. (B) New Zealand.

having less distinct morphological boundaries. Also, the genus includes both Australian and New Zealand endemic species, as well as species with trans-Tasman distributions, plus it is a critical habitat builder in the shallow subtidal waters around New Zealand and southern Australia.

\section{MATERIAL AND METHODS}

We sampled species of Cystophora from south-eastern Australia (southern Australia and Tasmania) and New Zealand, including the Chatham Islands (Table S1; Fig. 1). Other species were not identified in our study area (see text) or were from south-western/Western Australia (Womersley 1987). Thalli were pressed as voucher specimens and deposited in the herbarium of the Museum of New Zealand Te Papa Tongarewa (WELT) (Thiers 2017) (Table S1). Clean apices were detached and rapidly dried in silica gel for subsequent DNA extraction. A priori species assignments were made on the basis of morphological characters from Womersley $(1964,1987)$. Key diagnostic characters are listed in Table S2.

DNA was extracted from approximately $2-5 \mathrm{mg}$ of dry tissue using a modified cetyl trimethylammonium bromide buffer procedure (Zuccarello \& Lokhorst 2005), with the addition of $1 \%$ polyvinylpolypyrrolidone to the extraction buffer. A $615 \mathrm{bp}$ fragment from the $5^{\prime}$ end of the COI gene was amplified using primer pairs GAZF2 and GAZR2 (Lane et al. 2007) or GAZF2 and a new reverse primer, fcox $808 \mathrm{R}$ (5'-TAAACTTCGGGGTGTCCAAA). Amplification of ITS used either AFP2(F) (Peters \& Burkhardt 1998) or P1 (Tai et al. 2001) forward primers and KG4 reverse primer (Lane et al. 2006).

The polymerase chain reaction (PCR) mix for both regions contained $1 \mu \mathrm{l}$ genomic DNA, $0.5 \mathrm{U}$ Taq DNA polymerase [New England Biolabs (NEB), Ipswich, Massachusetts, USA], $1 \times$ ThermoPol reaction buffer $(\mathrm{NEB}), 7.5$ pmoles each primer, $200 \mathrm{nM}$ deoxynucleoside triphosphate and $0.01 \%$ bovine serum albumin. COI amplification used a PCR routine with an initial denaturation step of $94^{\circ} \mathrm{C}$ for 4 min; then 35 cycles of $1 \mathrm{~min}$ at $94^{\circ} \mathrm{C}, 30 \mathrm{~s}$ at $50^{\circ} \mathrm{C}$ and $1 \mathrm{~min}$ at $72^{\circ} \mathrm{C}$; with a final extension of $72^{\circ} \mathrm{C}$ for $7 \mathrm{~min}$. ITS amplifications used a touchdown PCR routine with an initial denaturation step of $94^{\circ} \mathrm{C}$ for $4 \mathrm{~min}$; then 5 cycles of $1 \mathrm{~min}$ at $94^{\circ} \mathrm{C}, 45 \mathrm{~s}$ at $55^{\circ} \mathrm{C}\left(-1^{\circ} \mathrm{C} /\right.$ cycle $)$ and $1 \mathrm{~min}$ at $72^{\circ} \mathrm{C}$; followed by 30 cycles of $1 \mathrm{~min}$ at $94^{\circ} \mathrm{C}, 45 \mathrm{~s}$ at $50^{\circ} \mathrm{C}$ and $1 \mathrm{~min}$ at $72^{\circ} \mathrm{C}$; with a final extension of $72^{\circ} \mathrm{C}$ for $10 \mathrm{~min}$. Amplified products were checked for length and yield on $1 \%$ agarose gels stained with ethidium bromide, then cleaned with ExoSap-IT enzymes (USB, Cleveland, Ohio, USA) and sequenced commercially (Macrogen Inc., Seoul, South Korea). Sequencing of COI fragments used the same primers as for amplification. ITS sequencing used the additional internal primers KP5 and KIR1 (Lane et al. 2006). Samples for interspecific analysis of some closely related species were also amplified and sequenced for the highly variable mitochon- 
drial spacer '23S-tRNA-Lys' (Hoarau et al. 2007), using primers as in Buchanan and Zuccarello (2012).

COI fragments were aligned using Geneious 9 (http:// www.geneious.com, Kearse et al. 2012). Alignment was straightforward with no gaps. ITS sequences were aligned using the MAFFT algorithm (Katoh et al. 2002). Phylogenetic trees were constructed with maximum likelihood (ML) using RAxML 7.2.8 (Stamatakis 2006) under the GTR + CAT model with partitioned codons for COI. Support for individual nodes was determined by 1000 bootstrap replicates. Bayesian trees were inferred using MrBayes 3.2 (Ronquist et al. 2012) under the GTR + gamma model for 3 million generations with two independent runs, a sampling frequency of 1000 and a burn-in of 300 trees. A combined dataset was also produced with the ITS and COI regions partitioned (plus codons in COI). Preliminary trees positioned Landsburgia as the most closely related genus to Cystophora, and Landsburgia quercifolia Harvey was chosen as the outgroup in all subsequent analyses.

The utility of genetic species delimitation methods using the DNA barcoding region of COI to recover morphologically identified samples was tested using three methods for COI and ITS: (1) distance-based [Automatic Barcode Gap Discovery (ABGD), web last modified 17 August 2016; Puillandre et al. 2012], (2) a tree-based method [Poisson-Tree processes (PTP); Zhang et al. 2013] and (3) a model-based method [Generalized Mixed Yule Coalescent (GMYC); Pons et al. 2006; Monaghan et al. 2009; Fujisawa \& Barraclough 2013]. All analyses were run with both the full dataset and a reduced dataset with identical sequences removed. ABGD was run with the following settings: $P_{\min }=0.001, P_{\max }=0.1$, steps $=10, \mathrm{X}$ (relative gap width) $=1.0, \mathrm{Nb}$ bin (distance distribution) $=20$ and Jukes-Cantor (JC69) or Kimura (K80) parameter models. We used the Bayesian variant of the PTP method (bPTP). The current version of the software (October 2016) used our RAxML COI, ITS and combined gene trees with 100,000 Markov chain Monte Carlo generations and thinning every 100. The ultrametric tree for GMYC was generated with BEAST 2.1 (Drummond et al. 2012) from COI and ITS alignments after removing identical sequences. A coalescent constant size tree prior (Kingman 1982) was set under an uncorrelated lognormal relaxed clock and GTR + gamma + invariant sites model. The analysis was set for 10 million generations and a sampling frequency of 1000 . Before performing the GMYC analyses, we checked the estimated sample size with Tracer 1.6 (Rambaut et al. 2014); sampling was continued until effective sample size values were $>200$. The maximum clade credibility tree was computed using TreeAnnotator 1.8.3 (Drummond et al. 2012). The resulting ultrametric tree was imported into the GMYC web server, running the single threshold (sGMYC, Pons et al. 2006).

Another approach, based on statistical parsimony, separates groups of sequences into different networks if the haplotypes are connected by long branches that are affected by homoplasy (Hart \& Sunday 2007). Networks were created using TCS 1.21 (Clement et al. 2000) to which the sequences could be joined with $95 \%$ confidence.

Receptacle length, width (wider axis of compressed receptacle) and breadth (narrower axis of compressed receptacle) of herbaria specimens of Cystophora scalaris
J.Agardh and Cystophora distenta J.Agardh were measured with digital callipers. In three specimens, selected as representing the range of receptacle size, measurements were taken of fresh receptacles. These receptacles were then airdried and re-measured using a factor estimated by regression to determine a multiplier to convert measurements from herbarium specimens to the equivalent fresh dimensions. Analyses of variance (ANOVAs), implemented in SPSS16, were used to test for significant differences between mean dimensions. In addition to these specimens, herbaria specimens of all New Zealand species of Cystophora were examined from WELT, and our collections and additional measurements were made to determine the range of character dimensions for revised descriptions.

\section{RESULTS}

\section{Species identification}

Most specimens were readily identified to species level using characters specified by Womersley (1964, 1987; Table S2). However, some specimens were difficult to assign to species using existing keys and morphological characters. For example, we found morphological intermediates between Cystophora retroflexa (Labillardière) J.Agardh and Cystophora subfarcinata (Mertens) J.Agardh. We were often unable to clearly distinguish Cystophora distenta from Cystophora scalaris, or Cystophora congesta Womersley \& Nizamuddin ex Womersley from Cystophora retroflexa using morphological data. Thus, our final dataset included 12 morphological species.

\section{Phylogeny and species delimitations}

We successfully amplified the COI region from 108 specimens of Cystophora (Genbank Accession numbers GU289232GU289344; Table S1), with the resulting phylogeny of both the full dataset (Fig. S1) and the reduced dataset (with identical sequences removed) being similar (Fig. 2); thus, our discussion will focus on the reduced data set. Cystophora moniliformis (Esper) Womersley \& Nizamuddin was sister to the other species of Cystophora. The remaining morphospecies of Cystophora had strong [e.g. C. scalaris, C. torulosa (R. Brown ex Turner) J.Agardh] to moderate support [e.g. $C$. retorta (Mertens) J.Agardh, $C$. siliquosa J.Agardh, $C$. subfarcinata (Mertens) J.Agardh]. Cystophora subfarcinata and $C$. retroflexa $/ C$. congesta were sister species but poorly resolved, as were $C$. torulosa and $C$. scalaris/C.distenta. There was no phylogenetic support for separating samples identified as $C$. retroflexa from samples identified as $C$. congesta, nor between samples identified as $C$. scalaris from samples identified as $C$. distenta (Fig. S1).

Genetic species delimitation methods delimited species of Cystophora differently when using the full COI dataset compared with the reduced dataset. The full dataset indicated ten species (PTP), nine species (ABGD) and two species (TCS). The reduced dataset indicated nine species (PTP), two species (ABGD) and six species (GMYC) within Cystophora. bPTP was able to distinguish $C$. subfarcinata from $C$. retroflexa $/ C$. congesta using the full dataset but placed them 


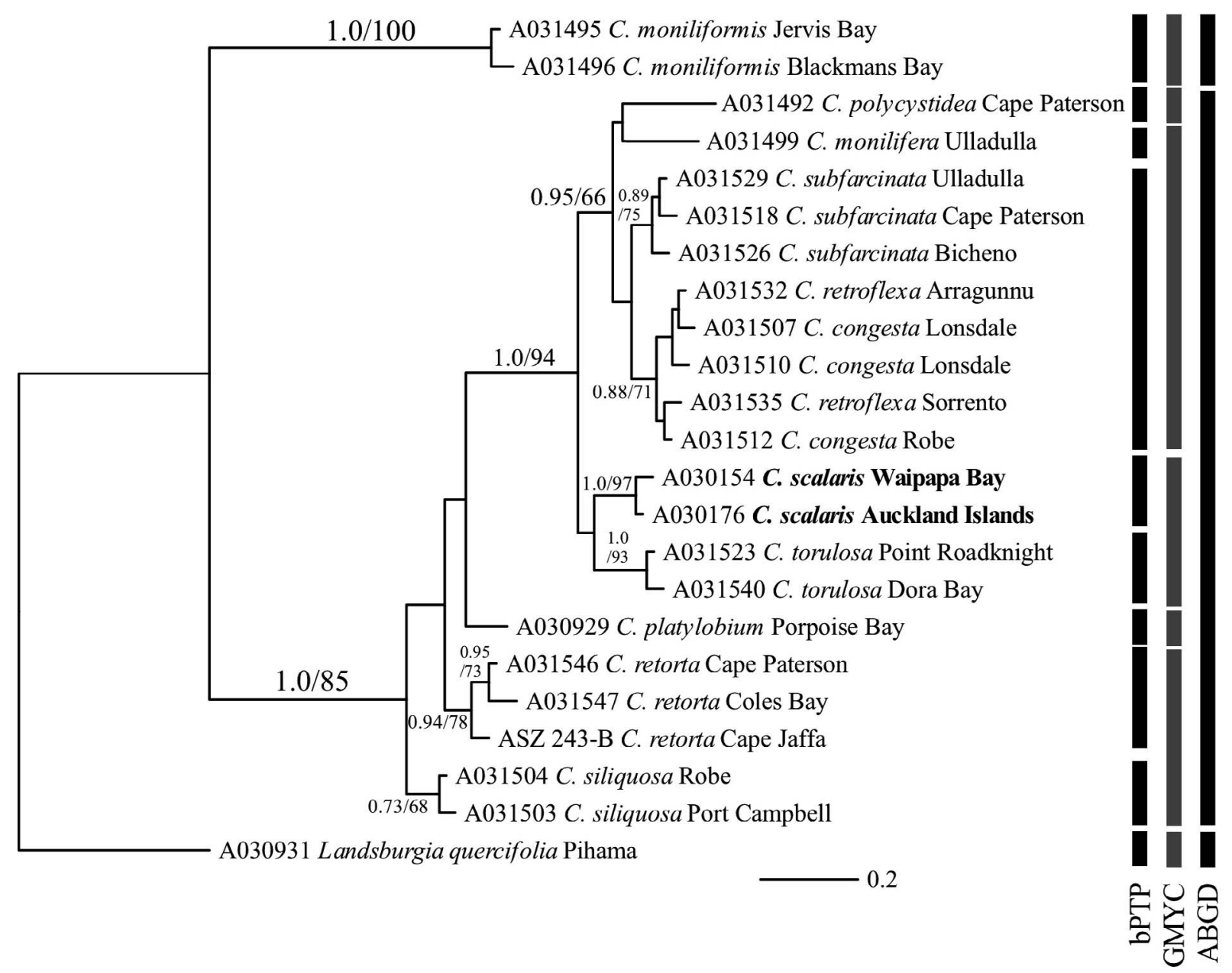

Fig. 2. Majority-rule consensus tree generated from the MrBayes analysis of the reduced COI dataset (identical sequences removed). Values on branches = Bayesian posterior probabilities (PP) followed by ML bootstrap percentages (BP). Values below $<0.7$ PP and $50 \%$ BP not shown. WELT voucher numbers shown (see Table S1 for details). Species delimitations indicated on right (for methods, see text). Samples in bold from New Zealand. Scale bar indicates the number of mutations per site. Outgroup is Landsburgia quercifolia.

in the same genetic species using the reduced dataset. ABGD grouped $C$. subfarcinata and $C$. retroflexa/C. congesta (full dataset) but was able to separate only C. moniliformis using the reduced dataset (Fig. 2). GMYC, using the reduced data set, was not able to separate the morphospecies $C$. subfarcinata/C. retroflexa/C. congesta/Cystophora monilifera J.Agardh, nor C. retorta/C. siliquosa J.Agardh.

The ITS dataset consisted of 47 specimens of Cystophora, plus the outgroup Landsburgia quercifolia (Genbank accession numbers GU289345-GU289392). The phylogeny was similar to the COI dataset but with some incongruences. Cystophora moniliformis was again sister to the remaining species but there was moderate support for the grouping of C. subfarcinata and C. torulosa (Fig. S2). Consistent with COI, phylogenies were not able to separate $C$. retroflexa from $C$. congesta nor $C$. scalaris from $C$. distenta. Species delimitation methodologies were not completely congruent with morphospecies. For example, PTP grouped many species into one large species group. On the other hand both ABGD and GMYC were congruent, indicating eight species of Cystophora. These two methods could not separate specimens identified as $C$.
retroflexa/C. congesta or C. scalaris/C. distenta, and did not separate C. subfarcinata from C. torulosa.

Analyses of combined COI and ITS data produced trees with reasonable support for most nodes but did not separate C. congesta $/ C$. retroflexa and $C$. scalaris $/ C$. distenta and did not show support for the position of Cystophora platylobium (Fig. 3). Most morphospecies were recognized by both bPTP and ABGD (although C. platylobium samples from New Zealand and Australia were recognized as separate genetic species with bPTP and ABGD), but again these combined data did not separate $C$. congesta from $C$. retroflexa nor $C$. scalaris from $C$. distenta.

\section{Morphology of Cystophora scalaris and Cystophora distenta}

Specimens identified as $C$. scalaris and $C$. distenta showed a wide range of receptacle forms, often with high levels of variation even on a single thallus (Figs 4, S3). Specimens from highly exposed locations (e.g. specimens 17-20, or WELT A030908-10 and WELT A031345 in Fig. 4) showed reduced receptacle lengths (below $1 \mathrm{~mm}$ ). Neither length nor width-tobreadth ratios (a measure of compression of the receptacle) 


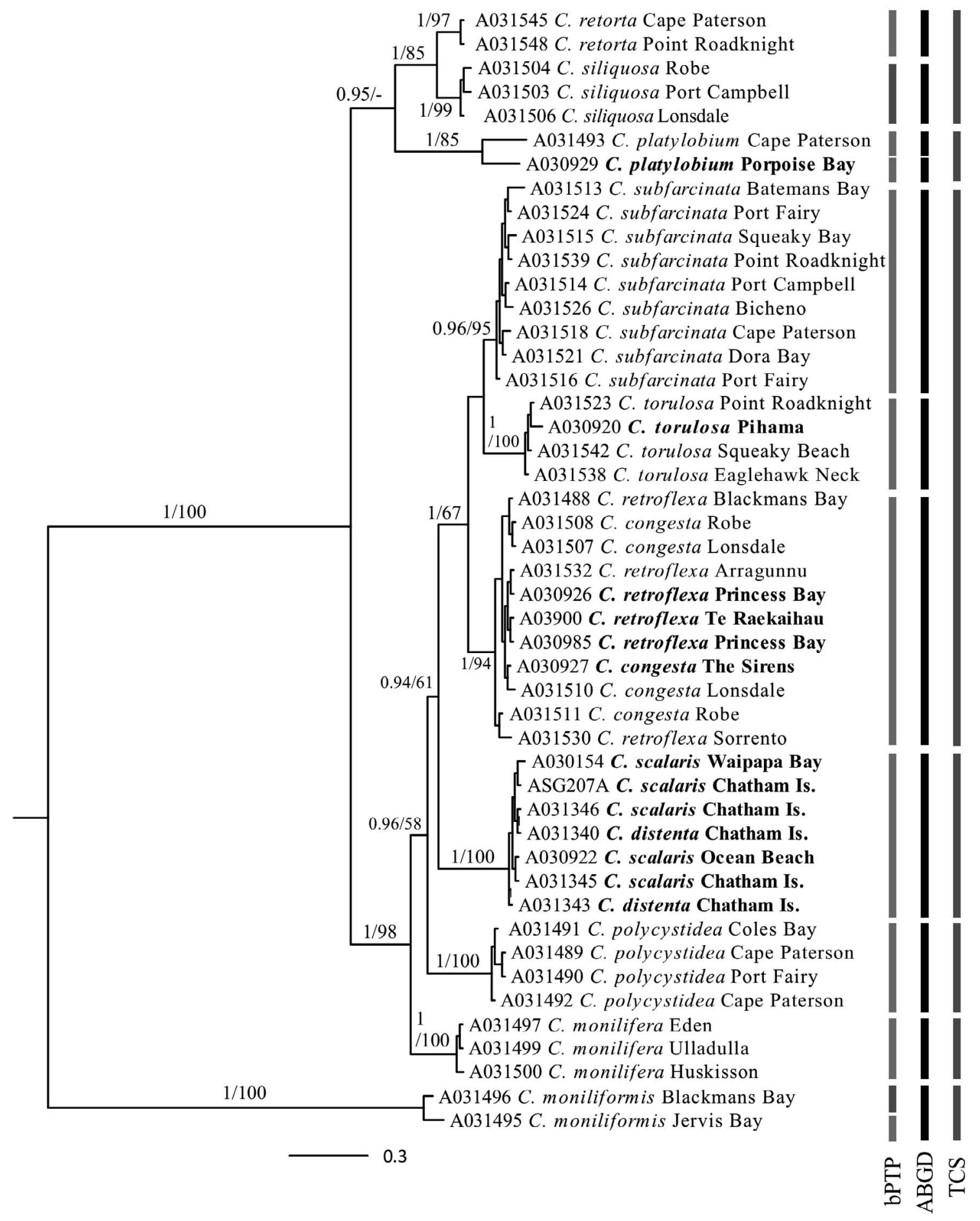

Fig. 3. Majority-rule consensus tree generated from the MrBayes analysis of combined COI and ITS datasets. Values on branches $=$ Bayesian posterior probabilities (PP) followed by ML bootstrap percentages (BP). Values below $<0.7$ PP and 50\% BP not shown. WELT voucher numbers shown (Table S1 for details). Species delimitations indicated on right (for methods see text). Samples in bold from New Zealand. Scale bar indicates number of mutations per site. Outgroup Landsburgia quercifolia removed for clarity.

showed clusters. ANOVA analysis of log-transformed data showed significant $(P<0.01)$ differences between means in the data but post hoc tests (Tukey's honest significant difference pairwise and range tests) showed that significant differences existed only between outlier data. For example, mean length of receptacles from specimens 4 (WELT A031337) and 15
(WELT A0A031335) (in Fig. 4A) were significantly different from specimens 16-20 (WELT A031345, WELT A030908-10) and 22 (WELT A030922) but differences between both groups and intermediate specimens were not significant $(P>0.05)$. Similarly, specimens with the greatest receptacle width-tobreadth ratios [specimens 13 (WELT A031336) and 25 

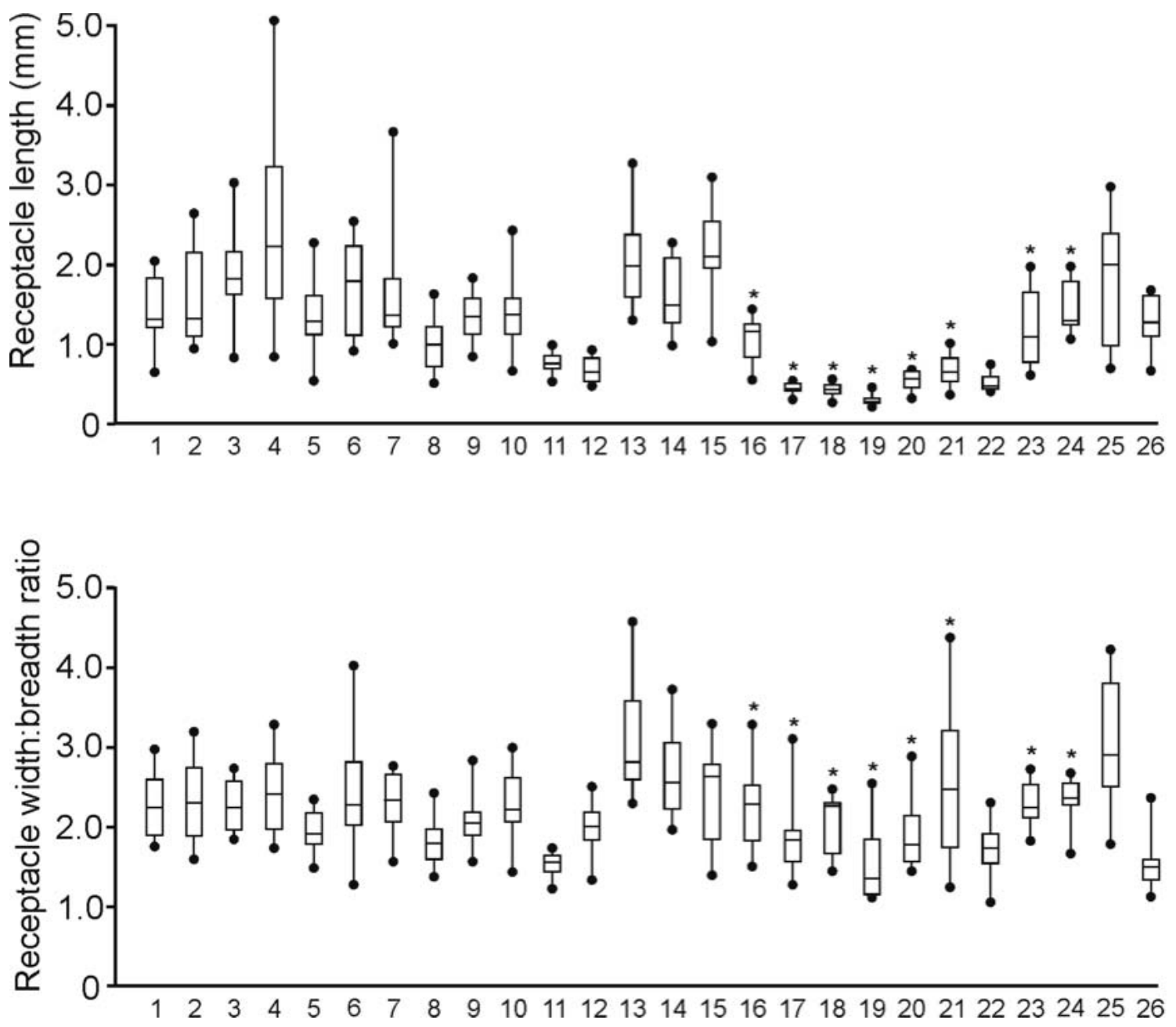

Fig. 4. Morphological variation from 26 specimens of Cystophora scalaris/Cystophora distenta (see Table S1 for information on specimens 126). Graphs show maximum, minimum, median and $25 \%$ and $75 \%$ quartiles. Data are arranged from northernmost (1) to southernmost (26) specimens, asterisks indicate specimens from the Chatham Islands. Specimens from highly exposed locations (e.g. specimens 17-20) show very reduced receptacle lengths. Upper graph $=(\mathrm{A})$ Receptacle length. Lower graph $=(\mathrm{B})$ Receptacle width-to-breadth ratios.

(WELT A030933) in Fig. 4B] showed significant differences from those specimens with the lowest ratios [specimens 11, 19 (WELT A030905, WELT A030908) and 26 (WELT A030906) in Fig. 4B] but none of these specimens showed significant differences from intermediate sized specimens. The morphological results strongly suggest that $C$. scalaris and $C$. distenta represent a single undistinguishable species.

\section{Haplotypes of Cystophora congesta from Cystophora retroflexa}

Four mitochondrial spacer haplotypes were found in Cystophora retroflexa and $C$. congesta (haplotypes A-D). Two haplotypes associated with $C$. subfarcinata were included (haplotypes E, F) in the haplotype network (Fig. 5; Table S3) (Genbank accession numbers JF309051-JF309070). Four specimens identified as either $C$. retroflexa or $C$. congesta were separated by a single change in each case (Fig. 5). Specimens with two haplotypes $(\mathrm{B}, \mathrm{C})$ were identified as either $C$. congesta or $C$. retroflexa. Only one specimen identified as C. congesta (WELT A031508 from Robe, South Australia) had a unique haplotype (Haplotype A; Fig. 5). Intermediates

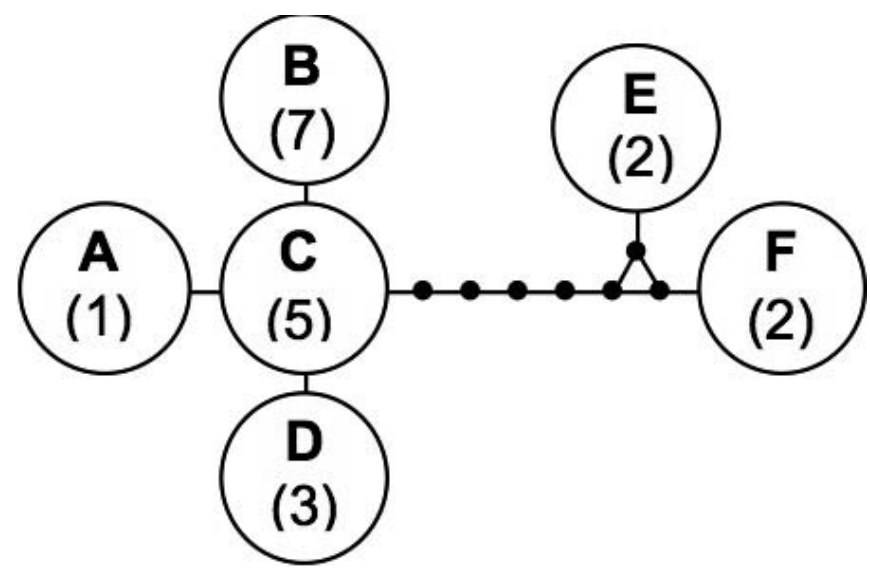

Fig. 5. Statistical parsimony network inferred from 20 mitochondrial spacer sequences of (A-D) Cystophora retroflexa and $C$. congesta and (E, F) C. subfarcinata. Estimated at $95 \%$ confidence. Haplotypes $\mathrm{B}$ and $\mathrm{C}$ include both $C$. retroflexa and $C$. congesta morphotypes. Number of samples in brackets. 
in morphology between $C$. retroflexa and $C$. congesta were also found (Fig. S4). These results suggest that $C$. retroflexa and $C$. congesta cannot be distinguished as separate species.

\section{DISCUSSION}

We showed that by using a combined COI and ITS dataset and genetic species delimitation methods, we are able to confirm the species status of many of the most common species of Cystophora in New Zealand and southern Australia. Most of the specimens of Cystophora investigated were identifiable by using existing morphological species descriptions. However, using the COI dataset alone, genetic species delimitation methods in some cases did not match morphologically identified species, and clustered morphological species into a single group. For example, $C$. retroflexa $/ C$. congesta $/ C$. subfarcinata were often grouped together (Figs 2, S1 with GMYC and ABGD, respectively). This lower number of delimitated species was especially evident with ABGD and TCS. It appears that COI alone is not able to separate all morphospecies in Cystophora.

While using DNA sequences to identify algae is an established technique (e.g. Lane \& Saunders 2005; Fox \& Swanson 2007), a prerequisite for extending this case-by-case molecular identification into a DNA barcoding system is to firmly establish the utility of one gene for identifying a wide range of species. Some previous studies using COI barcoding have either not discriminated species (Lane et al. 2007); not sampled sufficiently across relevant species ranges, risking underestimating intra-specific divergence (Kucera \& Saunders 2008); or not found a gap between intra- and interspecific genetic distances (Mattio \& Payri 2010). There are some reasons for this inability of a single mitochondrial marker to separate species: (1) differences in mutation rates between genes, age of species (Silberfeld et al. 2013); (2) concomitant incomplete lineage sorting of mitochondrial markers (Leliaert et al. 2014); and (3) the taxonomic oversplitting of morphological variation in genetically similar, or near identical, species.

Species delimitation methods using combined analysis of COI and ITS datasets more closely matched morphospecies descriptions using two methods: ABGD and bPTP (GMYC was not used, as the two markers are unlinked with different coalescent histories). The increased resolution with multiple markers has been shown in several studies (e.g. Montecinos et al. 2017) and provides evidence in Cystophora that most morphologically recognized species are genetically supported. Two pairs of closely related species of Cystophora $(C$. distenta/C. scalaris and $C$. retroflexa/C. congesta) were not separated by any combination of genes or morphological analyses.

Besides the previously mentioned species, some taxa were morphologically difficult to separate. Cystophora retroflexa and $C$. subfarcinata can resemble one another when young, infertile or stunted, but we were able to distinguish fertile specimens by shape of the conceptacle. In C. subfarcinata the conceptacle is spherical or subspherical; in C. retroflexa the conceptacles are elongate.
Cystophora siliquosa and $C$. retorta share complanate branched laterals, rounded axils and relatively straight main axes. Presence of vesicles is a diagnostic character for $C$. retorta but this is of limited value since vesicles are absent on some specimens (Womersley 1964, 1987). We were unable to distinguish species by the shape of the main axis (a character specified by Womersley 1987; see Table S2), and microscopic examination of conceptacles for determination of monoecy (for $C$. retorta) or dioecy (for $C$. siliquosa) was required to confidently assign specimens to species. In both these species pairs, low morphological divergence and plasticity made species assignments difficult.

Cystophora scalaris and C. distenta did not separate in any molecular analysis. Cystophora distenta was described by J. Agardh based on material from the Chatham Islands (Agardh 1870). The species has been reported from Wellington, New Zealand, southward and the Chatham Islands (Lindauer et al. 1961). It is similar to C. scalaris but with longer, broader and more torulose receptacles, but dimensions given by Womersley (1964) overlap (Table S2). Three specimens collected from the Chatham Islands and the South Island of New Zealand were considered sufficiently morphologically distinct to assign to $C$. distenta; whereas, other specimens showed intermediate morphologies and were assigned to $C$. scalaris. Analysis of receptacle shape did not show any significant pattern of morphological differences between samples or between samples from different areas.

Cystophora retroflexa and C. congesta are morphologically similar and were not distinguished in any molecular analysis (Figs 2, 3). Rather, haplotypes and ribotypes from $C$. congesta and $C$. retroflexa were intermixed. Womersley (1964, 1987) separated these species by vegetative characters but accepted that intergrades occurred. Cystophora retroflexa has longer $(20-60 \mathrm{~mm})$ receptacles and a more openly branched habit. Cystophora congesta has shorter (15-30 mm) receptacles and tufted laterals and ramuli, and usually ridges, on the primary axes. We assigned seven specimens to $C$. congesta, including three from the type locality (Robe, South Australia) but some species assigned to $C$. retroflexa (e.g. WELT A031533) tended toward a $C$. congesta-like morphology (Fig. S4). We consider that morphological characters used to separate $C$. distenta/C. scalaris and $C$. retroflexa/ $C$. congesta are continuous, and in the absence of molecular divergence oversplitting is probable.

While this is the best data available, DNA sequencing of a few markers may still not be able to resolve relationships between closely related sister species. Alternate methodologies, for example genotype-by-sequencing, have shown that single nucleotide polymorphisms (SNPs) can resolve previously unresolved relationships between species of Durvillaea (Fraser et al. 2016). Plus, microsatellite data can confirm species status and reveal hybridization (e.g. in Fucus, Wallace et al. 2004; Perrin et al. 2007; Pereyra et al. 2009).

Our genetic data confirms that three species of Cystophora (C. retroflexa, C. torulosa, C. platylobium) are found both in New Zealand and Australia. Genetic studies indicate that floating species are likely to continue to have gene flow even between distant populations (Fraser et al. 2009; Macaya \& Zuccarello 2010; Buchanan \& Zuccarello 2012). 
We were unable to confirm Cystophora cymodoceae Womersley \& Nizamuddin ex Womersley or $C$. cuspidata J.Agardh by either morphological characters, genetic distance or species delimitation analyses. We found no evidence for a distinct obligate epiphyte species equivalent to $C$. cymodoceae (Womersley 1987), despite sampling epiphytic specimens (e.g. WELT A031520, WELT A031502) from the type locality of C. cymodoceae (Duttons Beach, Victoria). No specimens could be unequivocally assigned to C. cuspidata. Cystophora cuspidata and C. subfarcinata are separated according to the arrangement and development of conceptacles (Womersley 1987). Cystophora cuspidata has receptacles that are broader (1.5-4 mm), with the lower conceptacles less scattered and arranged in two or three rows. Cystophora subfarcinata has narrower [(5-)10-30(-50) $\mathrm{mm}$ long $\times 1-2 \mathrm{~mm}]$ receptacles with usually scattered conceptacles. These characters intergrade, and some specimens could have been assigned to either species (e.g. WELT A031517). Specimens resembling $C$. cuspidata clustered with $C$. subfarcinata in the molecular analyses. We agree with Womersley (1987) that C. cuspidata is probably only a form of $C$. subfarcinata but we did not sample from the type locality of $C$. cuspidata (Encounter Bay, South Australia), nor did we find any specimens with conceptacles as prominent as those illustrated by Womersley (1987, fig. $149 \mathrm{H}$, p. 403). Therefore, we do not reduce $C$. cuspidata to synonymy with $C$. subfarcinata but recommend further work on these species.

In conclusion, we found no molecular evidence for the separate species status of $C$. distenta and $C$. congesta and suggest that further work is required to confirm the status of $C$. cuspidata and C. cymodoceae, plus other species of Cystophora from further west in southern Australia that were not sampled. Other sampled species were well supported by both morphological and molecular data. Our results suggest that COI barcoding might have utility in fucalean brown algae where delimiting closely related or sister species is not an issue (for example, in studies identifying invasive algae, or studies where generic identity of cryptic life stages is sufficient). For taxonomic decisions, a combination of markers, algorithmic species delimitation methods and careful re-examination of specimens is recommended. We also provide a revised key to the species of Cystophora in New Zealand (Table S4).

\section{Taxonomic amendments}

CYSTOPHORA CONGESTA AND CYSTOPHORA RETROFLEXA. According to Womersley $(1964$, p. 87) 'C congesta is most closely related to $C$. retroflexa, differing in the denser laterals and secondary axes, shorter receptacles and thicker, more rigid, primary axis. Occasional intergrades between these species occur'. Womersley then separated the species entirely on these vegetative characters, all of which are variable in other species of Cystophora. For example, specimens of $C$. retorta can have a thick primary axis and zig-zag laterals bearing fascicled ramuli and receptacles, and other specimens have a thin primary axis, with straight and sparsely branched laterals (Fig. S5).

Some specimens could be easily assigned to Cystophora retroflexa or $C$. congesta using Womersley's criteria but many specimens were intermediate and could be assigned to either species (Fig. S4). In other species of Cystophora, for example in $C$. siliquosa and $C$. subfarcinata (see dimensions in Womersley 1964), the presence of intergrades and the absence of genetic differentiation suggest the plasticity of these characters is inadequate for inferring distinct species.

\section{Cystophora retroflexa (Labillardière) J.Agardh}

REFERENCES: Womersley 1964, p. 89, figs 31, 32, pl. 10; Womersley 1987 , p. 396, fig. 2, figs 132 I, 146B, 149B, C. (as C. congesta).

HETEROTYPIC SYNONYM: Cystophora congesta Womersley \& Nizamuddin ex Womersley 1964, p. 86, fig. 30, pl. 9, fig. 2; Womersley 1987, p. 394. figs 146A, 149A.

AMENDED DESCRIPTION: Thallus brown, $0.3-1.5(-2) \mathrm{m}$ high, with the primary axes bearing alternate laterals and secondary axes. Holdfast discoid-conical, 3-15 mm diameter, with a short, terete stipe; epilithic. Primary axes compressed, 3-12 $\mathrm{mm}$ broad below and $1-4(-5) \mathrm{mm}$ thick, 2-6(-10) $\mathrm{mm}$ broad above, narrow edged; fairly straight to zigzag and scalariform; alternately distichously branched from the face of the axes; lower parts often denuded with prominent residues, each branch position giving rise to $1(-3)$ determinate laterals and $1(-2)$ indeterminate laterals; lower laterals usually retroflex, often with broad basal wings. Laterals determinate or indeterminate; determinate laterals arising from the edge of an outgrowth of the main axes, $20-100 \mathrm{~mm}$ long, with usually irregular radial, sometimes subtristichous or subdistichous branching, bearing ramuli, sometimes developing into receptacles; lower determinate laterals often with enlarged and flattened ramuli. Indeterminate laterals arising from the centre of outgrowths from the axes, 20-300 mm long; initially terete, becoming flattened, alternately distichously branched; becoming slightly to strongly zig-zag; bearing determinate secondary laterals and/or secondary indeterminate laterals. Ramuli 20-40(-50) $\mathrm{mm}$ long, 0.4-2(-3) mm broad. Ramuli on lower laterals sometimes enlarged and flattened. Vesicles ovoid, becoming subspherical when old; replacing basal (or lower two) ramuli of laterals, stalked, mutic, 4$12(-15) \mathrm{mm}$ long and $3-10(-12) \mathrm{mm}$ broad.

REPRODUCTION: Thalli monecious. Receptacles usually simple, occasionally branched, compressed, margins undulate to torulose when fresh, often strongly torulose when dried, 15-50(-60) $\mathrm{mm}$ long and $1-2(-4) \mathrm{mm}$ broad, attenuate at apex usually with sterile terminal awn, awn sometimes with scattered conceptacles, with two rows of conceptacles along the margins; conceptacles bisexual, ostioles along the margin.

TYPE LOCALITY: ‘Cape van Diemen' (southern Tasmania).

HOLOTYPE: FI (Herbarium Webbianum).

DISTRIBUTION: Australia: Womersley (1964) reports the species from Bondi (Sydney), New South Wales. We found specimens from Kiama, NSW southward. We have not ascertained the western limit of $C$. retroflexa in Australia. Womersley (1987) reports the western limit as 'from Cottesloe to Nannarup (Albany), Western Australia, and from Kangaroo I'. Tasmania; New Zealand, Chatham Islands.

CYSTOPHORA DISTENTA AND CYSTOPHORA SCALARIS. Agardh (1870) described Cystophra scalaris and $C$. distenta from the Chatham Islands but regarded them as contracted and distended forms of the same species, stating ' $C$. scalarem \& C. distentam esse ejusdem specie formas - unam contractam, alteram distentam' (Agardh 1870). ['C. scalaris and $C$. distenta are forms of the same species - one contracted and the other distended'.] De Toni $(1895$, p. 141) also stated that C. distenta was 'Anne forma laxa C. scalaris J. Ag.?'. Treatment as separate species seems to have begun with 
Laing (1901), who reported both forms as species without comment and continued to do so in further publications (Laing 1927). Lindauer (1947) followed Laing in listing these as separate species [but followed Gardner (1913) by using the generic name Blossevillea]. Lindauer (1947) gave the distribution of $C$. distenta (as Blossevillea distenta) as Chatham Islands and Stewart Island but noted that in Stewart Island 'the habit of the plant is less typical' (p. 560). Lindauer et al. (1961) reported the two entities as separate species, as did Womersley (1964, 1987), Nelson et al. (1991, 1992) and Adams (1994). Womersley (1964, p. 91) described $C$. distenta and $C$. scalaris as separate species, 'differing in the more compressed and longer receptacles, straighter and less robust axis, and looser branching' [in C. distenta]. This is unhelpful because the dimensions of the axis and looseness of branching are variable in many species of Cystophora (for example, in $C$. retorta; Fig. S5), and receptacle dimensions provided by Womersley (1964) and Lindauer et al. (1961), for these species overlap. Receptacles are variable in length in C. scalaris (Fig. 4), and our observations suggest compression is related to the reproductive state of the receptacle. Receptacle dimensions are highly variable, even on a single thallus.

Since we cannot separate Cystophora scalaris and $C$. distenta using morphological or molecular data, we consider the assessment of Agardh (1870) to be correct and regard $C$. distenta as a form of $C$. scalaris. The latter name has priority and is in more common usage (e.g. Morton \& Miller 1968; Shears \& Babcock 2007).

\section{Cystophora scalaris J.Agardh (1870, p. 442)}

REFERENCES: Womersley 1964, p. 82, figs 22, 23, pl. 7, fig. 2; Womersley 1964, p. 82, figs 22, 23, pl. 7, fig. 2 (as C. distenta).

HETEROTYPIC SYNONYM: C. distenta J.Agardh (1870, p. 442).

AMENDED DESCRIPTION: Thallus brown, (0.1-)0.3-1 m long, with the primary axes bearing alternate, openly to densely branched laterals and secondary axes. Holdfast discoid-conical, 5-20 $\mathrm{mm}$ diameter, with a short, terete stipe; epilithic. Primary axes strongly flattened, 3 $15(-20) \mathrm{mm}$ broad and 2-3 $\mathrm{mm}$ thick, strongly zig-zag and scalariform to fairly straight; lower parts often denuded with scalariform residues, alternately distichously branched from the face of the axis, with each branch position producing 1(-2) indeterminate secondary axes from the centre of the face and/or (0-1)-2 determinate laterals from the edge of the scales; laterals $10-30(-50) \mathrm{mm}$ apart; secondary and tertiary axes similar, 20-80 cm long, initially terete, becoming flattened, strongly zig-zag and scalariform to fairly straight; lower parts of primary, secondary and older tertiary axes usually denuded, with prominent, close-set scalariform residues and markedly broader basal wings on the primary (and often secondary) axis at branch positions. Laterals 20-80(-100) $\mathrm{mm}$ long, complanately branched, often bifurcate at their base, then alternately distichous with ramuli also alternately distichous; with acute to rounded axils; ultimate ramuli terete to compressed, 5-10(-30) $\mathrm{mm}$ long, 1-3(-4) $\mathrm{mm}$ broad. Ramuli of lower laterals on main axis often enlarged and flattened. Vesicles sparse to numerous; replacing lower 1 to 2 or more ramuli of the lateral of each bifurcation, subspherical to slightly ovoid, stalked, mutic, 2-8(-12) mm diameter.

REPRODUCTION: Thalli monoecious, receptacles developed from ultimate ramuli, simple or occasionally branched, ovoid to compressed in section, $10-50 \mathrm{~mm}$ long, $(0.5-) 1-3 \mathrm{~mm}$ broad and $1-1.5 \mathrm{~mm}$ thick, elongate; margins undulate to strongly torulose. Conceptacles bisexual, ostioles in two rows along the margins of the receptacle, rarely in three rows.

TYPE LOCALITY: Chatham Islands.

LECTOTYPE: LD (Herbarium Agardh, No. 1113).

DISTRIBUTION: New Zealand, from Wellington southward; Chatham Islands, Auckland Islands.

\section{ACKNOWLEDGEMENTS}

We thank the New Zealand Department of Conservation and Education NZ Study Abroad Scheme for funding assistance; Wendy Nelson, Tracy Farr, Kate Neill and the Department of Conservation Chatham Islands staff for assistance with collections and Alan Millar (National Herbarium of New South Wales) and Jenn Dalen (Museum of New Zealand Te Papa Tongarewa herbarium) for assistance with herbaria access. We thank Naomi Phillips for comments of previous drafts of the manuscript.

\section{SUPPLEMENTARY DATA}

Supplementary data associated with this article can be found online at http://dx.doi.org/10.2216/17-78.1.s1.

\section{REFERENCES}

Adams N.M. 1994. Seaweeds of New Zealand: an illustrated guide. Canterbury University Press, Christchurch, New Zealand. 360 pp.

Agardh J.G. 1870. Om Chatham-öarnes alger. Öfversigt af Kongl. Vetenskaps-Adademiens Förhandlingar, Stockholm 5: 435-456.

Buchanan J. \& Zuccarello G.C. 2012. Decoupling of short and long-distance dispersal pathways in the endemic New Zealand seaweed Carpophyllum maschalocarpum (Phaeophyceae, Fucales) Journal of Phycology 48: 518-529.

Cianciola E.N., Popolizio T.R., Schneider C.W. \& Lane C.E. 2010. Using molecular-assisted alpha taxonomy to better understand red algal biodiversity in Bermuda. Diversity 2: 946 958.

Clement M., Posada D. \& Crandall K.A. 2000. TCS: a computer program to estimate gene genealogies. Molecular Ecology 9: $1657-1659$.

De Toni G.B. 1895. Sylloge algarum omnium hucusque cognitarum III. Fucoideae. Sumptibus auctoris. Padua, Italy. 638 pp.

Díaz-Martínez S., Zuccarello G.C., Chávez G.A.S., Pedroche F.F. \& Avila-Ortiz A.G. 2016. Species of Padina (Dictyotales, Phaeophyceae) in tropical Mexican waters based on molecularassisted taxonomy. Phycologia 55: 673-687.

Drummond A.J., Suchard M.A., Xie D. \& Rambaut A. 2012. Bayesian phylogenetics with BEAUti and the BEAST 1.7. Molecular Biology and Evolution 29: 1969-1973.

Fox C.H. \& Swanson A.K. 2007. Nested PCR detection of microscopic life-stages of laminarian macroalgae and comparison with adult forms along intertidal height gradients. Marine Ecology Progress Series 332: 1-10.

Fraser C.I., Nikula R., Spencer H.G. \& Waters J.M. 2009. Kelp genes reveal effects of subantarctic sea ice during the last glacial maximum. Proceedings of the National Academy of Sciences of the United States of America 106: 3249-3253.

Fraser C.I., McGaughran A., Chuah A. \& Waters J.M. 2016. The importance of replicating genomic analyses to verify 
phylogenetic signal for recently evolved lineages. Molecular Ecology 25: 3683-3695.

Fujisawa T. \& Barraclough T.G. 2013. Delimiting species using single-locus data and the Generalized Mixed Yule Coalescent approach: a revised method and evaluation on simulated data sets. Systematic Biology 62: 707-724.

Gardner N.L. 1913. New Fucaceae. University of California Publications in Botany 4: 317-374.

González A., Beltrán J., Hiriart-Bertrand L., Flores V., de Reviers B., Correa J.A. \& Santelices B. 2012. Identification of cryptic species in the Lessonia nigrescens complex (Phaeophyceae, Laminariales). Journal of Phycology 48: 1153-1165.

Hart M.W. \& Sunday J. 2007. Things fall apart: biological species form unconnected parsimony networks. Biology Letters 3: 509512.

Hebert P.D.N., Cywinska A., Ball S.L. \& de WaArd J.R. 2003. Biological identifications through DNA barcodes. Proceedings of the Royal Society of London, Series B 270: 313-321.

Hebert P.D.N., Stoeckle M.Y., Zemlak T.S. \& Francis C.M. 2004. Identification of birds through DNA barcodes. PLoS Biology 2: e312. DOI: 10.1371/journal.pbio.0020312.

Hoarau G., Coyer J.A., Veldsink J.H., Stam W.T. \& Olsen J.L. 2007. Glacial refugia and recolonization pathways in the brown seaweed Fucus serratus. Molecular Ecology 16: 3606-3616.

Hoshino M., Ishikawa S., \& Kogame K. 2018. Concordance between DNA-based species boundaries and reproductive isolating barriers in the Scytosiphon lomentaria species complex (Ectocarpales, Phaeophyceae). Phycologia 57: 232-242.

Katoh K., Misawa K., Kuma K.-I. \& Miyata T. 2002. MAFFT: a novel method for rapid multiple sequence alignment based on fast Fourier transform. Nucleic Acids Research 30: 3059-3066.

Kingman J.F.C. 1982. The coalescent. Stochastic Processes and Their Applications 13: 235-248.

Kogame K., Ishikawa S., Yamauchi K., Uwai S., Kurihara A. \& MASudA M. 2015. Delimitation of cryptic species of the Scytosiphon lomentaria complex (Scytosiphonaceae, Phaeophyceae) in Japan, based on mitochondrial and nuclear molecular markers. Phycological Research 63:167-177.

Kucera H. \& SAunders G.W. 2008. Assigning morphological variants of Fucus (Fucales, Phaeophyceae) in Canadian waters to recognized species using DNA barcoding. Botany 86: 1065-1079.

LAING R.M. 1901. Revised list of New Zealand seaweeds. Transactions and Proceedings of the New Zealand Institute 32: 327-359.

LAING R.M. 1927. A reference list of New Zealand marine algae. Transactions of the New Zealand Institute 57: 126-185.

LANE C.E. \& SAunders G.W. 2005. Molecular investigation reveals epi/endophytic extrageneric kelp (Laminariales, Phaeophyceae) gametophytes colonizing Lessoniopsis littoralis thalli. Botanica Marina 48: 426-436.

Lane C.E., Mayes C., Druehl L.D. \& Saunders G.W. 2006. A multi-gene molecular investigation of the kelp (Laminariales, Phaeophyceae) resolves competing phylogenetic hypotheses and supports substantial taxonomic re-organization. Journal of Phycology 42: 493-512.

Lane C.E., Lindstrom S.C. \& Saunders G.W. 2007. A molecular assessment of northeast Pacific Alaria species (Laminariales, Phaeophyceae) with reference to the utility of DNA barcoding. Molecular Phylogenetics and Evolution 44: 634-648.

Leliaert F., Verbruggen H., Vanormelingen P., Steen F., LópezBautista J.M, Zuccarello G.C. \& De Clerck O. 2014. DNAbased species delimitation in algae (review). European Journal of Phycology 49: 179-196.

LiNDAUER V.W. 1947. An annotated list of the brown seaweeds, Phaeophyceae, of New Zealand. Transactions of the Royal Society of New Zealand 76: 542-566.

Lindauer V.W., Chapman V.J. \& Aiken M. 1961. The marine algae of New Zealand II: Phaeophyceae. Nova Hedwigia 3: 129-350.

Macaya E.C. \& Zuccarello G.C. 2010. DNA barcoding and genetic divergence in the giant kelp Macrocystis (Laminariales). Journal of Phycology 46: 736-742.

Mattio L. \& PAyri C. 2010. Assessment of five markers as potential barcodes for identifying Sargassum subgenus Sargassum species (Phaeophyceae, Fucales). Cryptogamie, Algologie 31: 467-485.
McDevit D.C. \& SAunders G.W. 2010. A DNA barcoding examination of the Laminariaceae (Phaeophyceae) in Canada reveals novel biogeographical and evolutionary insights. Phycologia 49: 235-248.

Monaghan M.T., Wild R., Elliot M., Fujisawa T., Balke M., Inward D.J.G., Lees D.C., Ranaivosolo R., Eggleton P., Barraclough T.G. \& Vogler A.P. 2009. Accelerated species inventory on Madagascar using coalescent-based models of species delineation. Systematic Biology 58: 298-311.

Montecinos A.E., Couceiro L., Peters A.F., Desrut A., Valero M. \& Guillemin M.-L. 2017. Species delimitation and phylogeographic analyses in the Ectocarpus subgroup siliculosi (Ectocarpales, Phaeophyceae). Journal of Phycology 53: 17-31.

Morton J.E. \& Miller M.C. 1968. The New Zealand sea shore. Collins, London, Auckland. 653 pp.

Nelson W.A., Adams N.M. \& Hay C.H. 1991. Marine algae of the Chatham Islands. National Museum of New Zealand, Miscellaneous Series 23: 1-58.

Nelson W.A., Adams N.M. \& Fox J.M. 1992. Marine algae of the northern South Island. A list of species. National Museum of New Zealand, Miscellaneous Series 26: 1-79.

Pereyra R.T., Bergström L., Kautsky L. \& Johannesson K. 2009. Rapid speciation in a newly opened postglacial marine environment, the Baltic Sea. BMC Evolutionary Biology 9: 70-79.

Perrin C., Daguin C., Vliet M.V.D., Engel C.R., Pearson G.A. \& SERRÃo E.A. 2007. Implications of mating system for genetic diversity of sister algal species: Fucus spiralis and Fucus vesiculosus (Heterokontophyta, Phaeophyceae). European Journal of Phycology 42: 219-230.

Peters A.F. \& Burkhardt E. 1998. Systematic position of the kelp endophyte Laminarionema elsbetiae (Ectocarpales sensu lato, Phaeophyceae) inferred from nuclear ribosomal DNA sequences. Phycologia 37: 114-120.

Peters A.F., Couceiro L., Tsiamis K., Küpper F.C. \& Valero M. 2015. Barcoding of cryptic stages of marine brown algae isolated from incubated substratum reveals high diversity in Acinetosporaceae (Ectocarpales, Phaeophyceae). Cryptogamie, Algologie 36: $3-29$.

Pons J., Barraclough T.G., Gomez-Zurita J., Cardoso A., Duran D.P., Hazell S., Kamoun S., Sumlin W.D. \& Vogler A.P. 2006. Sequence-based species delimitation for the DNA taxonomy of undescribed insects. Systematic Biology 55: 595-609.

Puillandre N., Lambert A., Brouillet S. \& Achaz G. 2012. ABGD, Automatic Barcode Gap Discovery for primary species delimitation. Molecular Ecology 21: 1864-1877.

Rambaut A., Suchard M.A., Xie D. \& Drummond A.J. 2014. Tracer v1.6. Retrieved from http://tree.bio.ed.ac.uk/software/ tracer.

Ronguist F., Teslenko M., van der Mark P., Ayes D.L., Darling A., Höhna S., Lerget B., Liu L., Suchard M.A. \& Huelsenback J.P. 2012. MrBayes 3.2: efficient Bayesian phylogenetic inference and model choice across a large model space. Systematic Biology 61: $539-542$

SheARs N.T. \& Babcock R.C. 2007. Quantitative description of New Zealand's shallow sub-tidal reef communities. Science for Conservation 280. Wellington, New Zealand, New Zealand Department of Conservation. $126 \mathrm{pp}$.

Silberfeld T., Bittner L., Fernández-García C., Cruaud C., Rousseau F., de Reviers B., Leliaert F., Payri C.E. \& De ClerCK O. 2013. Species diversity, phylogeny and large scale biogeographic patterns of the genus Padina (Phaeophyceae, Dictyotales). Journal of Phycology 49: 130-142.

Stamatakis A. 2006. RAxML-VI-HPC: Maximum likelihoodbased phylogenetic analyses with thousands of taxa and mixed models. Bioinformatics 22: 2688-2690.

Tai V., Lindstrom S.C. \& Saunders G.W. 2001. Phylogeny of the Dumontiaceae (Gigartinales, Rhodophyta) and associated families based on SSU rDNA and internal transcribed spacer sequence data. Journal of Phycology 37: 184-196.

ThIERS B. 2017. (continuously updated). Index Herbariorum: a global directory of public herbaria and associated staff. New York Botanical Garden's Virtual Herbarium. http://sweetgum.nybg. org/ih/; searched on 17 June 2017. 
Vieira C., D'hondt S., De Clerck O. \& Payri C.E. 2014. Toward an inordinate fondness for stars, beetles and Lobophora? Species diversity of the genus Lobophora (Dictyotales, Phaeophyceae) in New Caledonia. Journal of Phycology 50: 1101-1119.

Wallace A.L., Klein A.S. \& Mathieson A.C. 2004. Determining the affinities of salt march fucoids using microsatellite markers: evidence of hybridization and introgression between two species of Fucus (Phaeophyta) in a Maine estuary. Journal of Phycology 40: 1013-1027.

Womersley H.B.S. 1964. The morphology and taxonomy of Cystophora and related genera (Phaeophyta). Australian Journal of Botany 12: 53-110.
Womersley H.B.S. 1987. The marine benthic flora of southern Australia. Part II. South Australian Government Printing Division, Adelaide. $481 \mathrm{pp}$.

Zhang J., Kapli P., Pavlidis P. \& Stamatakis A. 2013. A general species delimitation method with applications to phylogenetic placements. Bioinformatics 29: 2869-2876.

ZuCCARELlo G.C. \& LoKhorst G.M. 2005. Molecular phylogeny of the genus Tribonema (Xanthophyceae) using $r b c \mathrm{~L}$ gene sequence data: monophyly of morphologically simple algal species. Phycologia 44: 384-392.

Received 20 June 2017; accepted 23 January 2018 